\title{
ПАРАДИГМАТИЧЕСКИЕ ОТНОШЕНИЯ ОНОМАТОПОВ В РУССКОМ И КУМЫКСКОМ ЯЗЫКАХ
}

\section{PARADIGMATIC RELATIONS OF ONOMATOPES IN RUSSIAN AND KUMYK LANGUAGES}

\section{S. Alieva}

Summary: The article is devoted to the study of paradigmatic relations of onomatopoeic words in the languages of different systems. Macro- and microparadigms of onomatopes is reviewed. The analysis showed that the most common Russian and Kumyk onomatopes enter into synonymous relations. The phenomenon of antonymy is less typical for these words, has a specific character, often manifests in an implicit form and is more characteristic of the Kumyk language. Homonyms among onomatopes are rare in both languages.

Keywords: agglomerate, antonym, lexico-semantic group, onomatop, paradigm, seme, synonym.
B современной лингвистике остается актуальной проблема системной организации лексики. Необходимость анализа системных свойств языковых единиц вообще (ономатопов в частности) вызвана стремлением осмыслить общелингвистические закономерности.

Для лексики как системного образования большое значение имеют парадигматические и синтагматические связи ее единиц. Лексические парадигмы составляют языковые единицы, противопоставленные по дифференциальным признакам. Как правило, парадигматические отношения связаны с рядом лексико-семантических категорий, прежде всего синонимии, антонимии, омонимии. В лексические парадигмы могут объединяться и слова, входящие в одну лексико-семантическую группу. Примером макропарадигмы способно выступать и лексико-семантическое поле.

«Парадигматические отношения характеризуют строение любых группировок или классов», которые выделяются в языке по принципу общности (формальной или семантической) их членов. В то же время подобные группировки противопоставляются друг другу по одному из этих оснований [6, с. 366].

Цель данной статьи - проанализировать парадигматические отношения между ономатопами в русском и кумыкском языках.

\author{
Алиева Самая Азеровна \\ к.филол.н., доцент, Дагестанский государственный \\ университет, г. Махачкала \\ samaya.alieva.00@mail.ru
}

Аннотация: Статья посвящена исследованию парадигматических отношений ономатопоэтических слов в разносистемных языках. Рассмотрены макро- $и$ микропарадигмы ономатопов. Анализ показал, что наиболее часто русские и кумыкские ономатопы вступают в синонимические отношения. Явление антонимии для данной группы слов менее характерно, имеет специфический характер, нередко проявляется в имплицитной форме и больше свойственно кумыкскому языку. Омонимы-ономатопы встречаются редко в обоих языkax.

Ключевые слова: агломерат, антоним, лексико-семантическая группа, ономатоп, парадигма, сема, синоним.

Лексический состав языка можно представить как систему взаимосвязанных семантических полей. Разновидностью семантического поля является лексико-семантическое поле, в котором по семантическому принципу объединены слова. Лексико-семантическое поле ономатопов представляет собой гетерогенное образование, включающее лексемы с различным частеречным статусом. В первую очередь в это поле войдут ономатопоэтические глаголы (мяукать, квакать, каркать; мавулламакъ, гюрюллемек, гъанцылламакъ) и отглагольные имена существительные (мяуканье, кваканье, квак, карканье; мавуллав, гюрюллев, дырыллав), связанные отношениями производности. Наряду с морфологическими оформленными словами в данное поле мы включаем и непосредственно звукоподражания (мяу, кар, ква; мияв, къакъ, бакъ) - примарно мотивированные ономатопы. Следует отметить ряд особенностей, которые отличают ЛСП ономатопов. Этому полю характерна непроницаемость границ для фонетических инноваций, поэтому все многообразие звучания передается за счет собственных (внутренних) ресурсов поля.

Рассмотрим микропарадигму в составе ЛСП ономатопов. Такой микропарадигмой выступает лексико-семантическая группа звукоподражательных глаголов.

Семен Семушкин и Ленька Ухарев смеялись почти до слез, а Мишка Астраханец и Савелка Лобан визжали от смеха, парни зычно гоготали, девчонки боязливо перешептывались да попискивали от страха (А. Патреев. 
Инженеры). Все вышеприведенные глаголы (смеялись визжали - гоготали - перешептывались - попискивали) представляют гетерогенные агломераты. Объединяет их интегральная сема «издавать звук». По мнению Л.А. Гороховой, агломераты от случайных сочетаний отличает то, что, во-первых, они объединены общей мыслью, а во-вторых, им свойственна общая функция [4, с. 12]. В Словаре синонимов русского языка 3.Е. Александровой из перечисленных ономатопоэтических глаголов представлены лишь два: смеяться и гоготать [1, с. 408]. Слова визжать и пищать являются контекстуальными синонимами. Кроме того, семные структуры значения этих глаголов содержат семы интенсивности и эмоциональности звучания. При этом следует отметить, что сема эмоциональности звучания в глаголе визжать не имеет ярко выраженной отрицательной коннотации благодаря контекстуальному окружению (om смеха). Несколько необычно наличие в приведенном синонимическом ряду лексемы пищать, которая употреблена в сочетании со словами от страха. Несмотря на то, что смех выражает различные чувства, однако в большинстве случаев они положительные, о чем свидетельствует другой пример: Дед приходит в неописанный восторг, заливается веселым смехом и кричит (Чехов. Ванька). «Дед язып гёрсетли батайгъан халда шатланып, шуйунчлу кюлкюге батыла (Чехов. Ванка)». Для передачи подобных звуков в кумыкском языке использовано кюлкюге батыла, что буквально означает «утопает в смехе».

Синонимический ряд ономатопоэтических глаголов может включать единицы различной стилистической маркированности. Нередко такие слова не обнаруживают между собой четких оттенков значения. «Многие звукоподражательные глаголы проявляют тенденцию к многозначности, что позволяет им входить сразу в несколько синонимических рядов [10, с. 223]. Это можно объяснить тем, что субъекты звучания издают звуки, которые совпадают по акустическим признакам.

Вот забулькали-затренькали бубенцы с колокольцами (В. Шишков. Угрюм-река). Контекстуальные синонимы забулькали-затренькали представлены как композитное образование. Данные синонимы можно назвать и индивидуально-авторскими. Если глагол тренькать и обозначает тонкие отрывистые звуки (поэтому понятно его сочетание с лексемой бубенцы), то слово булькать передает в большей мере звуки, «похожие на звуки жидкости, выливаемой из узкогорлового сосуда» [8, с. 68]. Обратившись к Русско-кумыкскому словарю, находим булькать «болкулламакъ, бокъурламакъ». Вода булькаem «Сув бокъурлай» [9, с. 78]. Аналогично представлено слово и в Кумыкско-русском словаре. Бокъурламакъ (бокъурамакъ) «клокотать, бурлить (о воде, нефти); булькать» [7, с. 61]. Таким образом, в кумыкском языке анализируемая лексема употребляется со словами, обозначающими жидкость. Соответствия русскому глаголу тренькать в двуязычном словаре нет, что вполне объяснимо пометой разг., имеющейся в Словаре русского языка. Однако в кумыкском языке есть глагол зангыратмакъ, который может быть употреблен вместо русских глаголов звенеть, бренчать, бряцать, тренькать. Къонкурав зангырлай «Колокол звенит (бренчит, тренькает)».

Он [внучек] не говорил, а верещал (В. Ерофеев. Москва-Петушки). В данном предложении глаголы говорить и верещать выступают как контекстуальные синонимы, которые помогают избежать тавтологии. «Через цепочку нанизывания синонимов говорящий пытается прояснить смысл сообщаемого» [5]. Можно отметить здесь и восходящую градацию, позволяющую глаголу верещать входить сразу в две лексико-семантические группы: глаголов речи, говорения и звукоподражательных глаголов, так как верещать - издавать без умолку резкие, визгливые звуки [2, с. 418].

Состав компонентов, которые образуют семантическую структуру значения ономатопов, в первую очередь ономатопоэтических глаголов, различается. Ряд глаголов имеет сходный набор компонентов. Возьмем, к примеру, синонимический ряд бабахать - бахать брякать - бухать - грохать. Все они в своем прямом значении обозначают сильные низкие звуки. Следует отметить, что условный и приблизительный характер ономатопов объясняет тот факт, что явление синонимии пронизывает всю категорию звукоподражаний.

По дифференциальным семам внутри микропарадигмы ономатопоэтических глаголов можно выделить подпарадигмы. В зависимости от того, какой признак будет принят за основу, выделяются глаголы интенсивного, эмоционального и конкретного звучания.

Глаголы интенсивного звучания имеют словесные конкретизаторы: сильный, резкий, громкий, пронзительный. В русском языке к ним относятся: гоготать, рычать, рявкать, реветь, вопить, клекотать. Подобная группа глаголов есть и в кумыкском языке, однако она менее многочисленна, что объясняется наличием в русском языке большого количества слов, обозначающих конкретное звучание и вследствие этого не нуждающихся в опоре на контекст. В кумыкском языке русский звукоподражательный глагол конкретного звучания нередко передается глаголом общего значения: акъырмакъ, къычырмакъ «кричать». Кумыкские глаголы с семой интенсивности звучания: акъырмакъ, улумакъ «выть», къагъылламакъ «гоготать», къычырмакъ.

Сема эмоциональности звучания чаще всего появляется у ономатопов в контексте, однако в русском языке существует ряд глаголов, которые имеют в семной структуре значения данную сему: вопить, мурлыкать, ворковать, выть, рычать. Немногочисленна эта группа и в ку- 
мыкском языке: гюрюллемек «ворковать», мырылламакъ «мурлыкать», гьанцылламакъ «скулить».

Сема способа звучания позволит объединить такие лексемы, как свистеть, шипеть, фыркать, цыкать; пышгъырмакъ «фыркать», жыжылламакъ «шипеть», сызгъырмакъ «свистеть».

Сема характера издаваемого звука входит в семантическую структуру значения русских глаголов ворковать, фыркать, цыркать, пыхтеть, клекотать, гоготать. Есть такие глаголы и в кумыкском языке: гюрюллемек, пышгъырмакъ, къагъылламакъ.

Таким образом, можно обнаружить одни и те же лексемы в разных лексико-семантических группах. «Члены одной и той же ЛСГ потенциально являются функционально-эквивалентными друг другу» [3, с. 102]. Общая функция, которую выполняют ономатопы, позволяет им заменять друг друга в определенных контекстах, несмотря на то, что значения таких слов являются не одинаковыми, а сходными. Все это происходит благодаря наличию интегральной семы (или сем), которая имеется в значениях всех слов, составляющих данную лексикосемантическую группу. Особенно ярко это проявляется, если сопоставить идентичные контексты на разных языках. Единая текстовая база позволяет оперировать эквивалентными лексемами: Тут Соловей являть свое искусство стал: Защелкал, Засвистал, На тысячу ладов тянул, переливался (И. Крылов. Осел и Соловей). «Сонг Бюлбюл де тёбен бутакъгъа тюшюп, Минг передеден аваз чыгъарып сарнай (И. Крылов. Ишек ва Бюлбюл)». Гетерогенные агломераты русского языка защелкал, засвистал, выступающие как контекстуальные синонимы, выполняют в первую очередь звукоизобразительную функцию. В кумыкском примере им соответствует глагол сарнай «щебечет». Кроме того, употреблено сочетание аваз чыгъарып «звук извлекающий». При переводе использован прием опущения.

Интерес представляет и следующий пример: Море шумит, шумит (М. Горький. Рождение человека). «Денгиз вашыллай, оькюре (М. Горкий. Адамны тувушлувуну)». Гомогенные агломераты русского языка переданы на кумыкский гетерогенными агломератами вашыллай «шумит» и оькюре «ревет». В данном случае использован прием добавления. О синонимических отношениях можно говорить лишь в кумыкском языке. В русском языке, чтобы подчеркнуть звукоизобразительную функцию глагола, писатель употребил прием повтора.

Синонимические парадигмы ономатопов можно исследовать и на примере имен существительных, обладающих особенными выразительными возможностями. Все трое [киргизов] вдруг вскочили на коней, со страшным, внезапным гиком пустились скакать во весь дух, куда лошади угодно, продолжая неистовый рев свой (Даль. Полунощник). Слова гик и рев являются синонимами и обозначают очень громкие звуки. Особенность звучания находит подтверждение и в контексте: этому способствуют прилагательные страшный, неистовый.

Все слушали их [снарядов] пронзительный визг и свист <...> А визг усиливается, переходит в страшный скрежет. Будто огромные чугунные пластины трут одна о другую, и они верезжат, и стонут, и скрежещут невыносимым скрежетом (Д. Фурманов. Чапаев). В приведенном отрывке сочетаются гетерогенные визг, свист, скрежет; верезжат, стонут и скрежещут и гомогенные агломераты скрежет, скрежещут. Автор одновременно употребляет ономатопоэтические глаголы и существительные, что усиливает производимое впечатление. При этом следует отметить, что ономатопы здесь выступают и в прямом, и в переносном значении. Отношения внутри синонимической парадигмы настолько сложны и многоплановы, что в некоторых случаях «данная микросистема выходит за пределы синонимического ряда» [11, с. 170]. Крайние единицы ряда перестают быть синонимами.

Шум табунов, мычанье стад Уж гласом бури заглушались (А. Пушкин. Кавказский пленник). «Йылкъы къавгъа, гезив мулар Боранда сырыклей еди (А. Пушкин. Кавказ есери). Контекстуальные синонимы (ономатопоэтические существительные) шум, мычанье переданы на кумыкский язык одной лексемой къавгъа «шум». Использован прием опущения.

Схожесть ономатопов по какому-либо признаку позволяет им вступать в синонимические отношения. Что касается отношений противопоставленности (антонимических), то об этом следует сказать особо. Принято считать, что звуку должен быть противопоставлен незвук. Но, по мнению С.А. Филимоненко, в этом ошибка ряда исследователей, которые не учитывают особенность семантики ономатопов, в первую очередь глаголов. Значения таких слов тесно «переплетены с акустическими характеристиками звука» [10, с. 224]. По этим характеристикам и могут быть противопоставлены ономатопы. 1)В семье Горячевых вышел какой-то шум и раздор, о котором всякий орет, а иной и шепчет, перегородя рот (Даль. Приемыш). Основанием для противопоставления глаголов является сема интенсивности звучания. Здесь противопоставляются громкие (орет) и тихие (menчет) звуки. 2)О, это не гавканье по зайцу - это отчаянный вой, это лютый, неистовый лай, это и плач и хохот вместе (Даль. Охота на волков). В этом предложении сочетаются контекстуальные синонимы (гавканье, вой, лай) и антонимы (плач и хохот). Антонимы плач и хохот противопоставляются не только по своим акустическим параметрам, но и семантически. 
Особенностью антонимических отношений, характерных для ономатопов, следует признать и явление энантиосемии (внутрисловной антонимии). Это явление затрагивает в большей степени кумыкский язык. Согласно лексикографическим источникам, лексема гюрюллемек может быть переведена на русский язык по-разному, в зависимости от источника звучания: «греметь, ворковать, реветь, квакать, курлыкать». Что еще раз подчеркивает отсутствие у большинства кумыкских ономатопов семы конкретного звучания. Однако наиболее часто она употребляется со словом гёгюрчюн «голубь». Гёгюрчюн гюрюллей. «Голубь воркует». В русском языке также можно обнаружить случаи внутрисловной антонимии. Иллюстрацией служит глагол фыркать, обозначающий смех и брюзжание. Слова могут противопоставляться и по семе эмоциональности звучания.

Я так мекаю: ежели поселимся вот тут, во лесочке, на большой травке, пожалуй, лихоманку на сто годов наживешь (А. Патреев. Инженеры). В Словаре русского языка С.И. Ожегова слово мекать имеет два значения: 1) об овцах, козах: издавать характерные звуки, напоминающие ме- и 2) Говорить неясно, с остановками [8, с. 347]. [Овцы] останавливались пугливо, и опять бежали, и мекали (Сергеев-Ценский. Движения). В словарном толковании в обоих случаях в семной структуре глагола мекать сохраняется сема «издавать, произносить звуки». Однако, обратившись к Словарю синонимов русского языка, находим ссылку см. думать [1, с. 177]. Именно в этом значении и употреблено слово мекаю в романе А. Патреева. Таким образом, здесь можно наблюдать явле- ние омонимии. Глагол мекать (думать) входит в лексико-семантическую группу глаголов мысли и не содержит сему «издавать звук». Кроме того, он имеет и специальные пометы разг., прост. Явление омонимии у ономатопов лучше исследовать на примере немотивированных слов. Такие звукокомплексы представлены в Словаре русских фоносемантических аномалий С.С. Шляховой. Обычно тик-так обозначает звук удара, тиканье часов. Однако лексикографический источник приводит и другое значение: хорошее положение дел [12, с. 140]. В Кумыкско-русском словаре шаркъ тоже выступает как омоним. Данное слово можно перевести по-разному: в сочетании с лексемами деп бегитмек «защелкнуть»; «хруст, треск». Есть и устаревшее значение «восток» [7, с. 351]. Но явление омонимии не получило широкого распространения у ономатопов.

Проведенный анализ лексических парадигм разносистемных языков позволил прийти к выводам, что русские и кумыкские ономатопы чаще всего способны вступать в синонимические отношения. Это подтверждают лексикографические источники и иллюстративный материал из художественной литературы. Синонимы позволяют избегать повторов и уточнять значения звукоподражаний. Явление антонимии встречается реже, имеет специфический характер и проявляется в ряде случаев в имплицитной форме энантиосемии. Внутрисловная антонимии больше характерна для кумыкского языка. Омонимы-ономатопы - достаточно редкое явление для лексических систем русского и кумыкского языков.

\section{ЛИТЕРАТУРА}

1. Александрова 3.Е. Словарь синонимов русского языка: Практический справочник. 6-е изд., перераб. и доп. - М.: Русский язык, 1980. - 495 с.

2. Большой академический словарь русского языка: РАН, Институт лингвистических исследований. - М. - СПб: Наука, 2005. Т. 2. Благо-Внять. - 661 с.

3. Боровикова Н.А. Функциональная эквивалентность базовых глаголов лексико-семантических групп // Проблемы глагольной семантики. Сборник научных трудов. - Свердловск: УрГУ, 1984. - С. 102- 107.

4. Горохова Л.А. Семантико-прагматические и социолингвистические особенности функционирования ономатопов в текстах современного английского языка: автореф. дис. ... канд. филол. наук. - Пятигорск, 1998. - 21 с.

5. Корсунова И.Н. Парадигматические отношения абстрактных существительных с собственно дейктическим значением // Современные проблемы науки и образования. 2014. № 6. - http://www.science-education.ru/ru/article/view?id=15746 (дата обращения 23.07.2020).

6. Кубрякова Е.С. Парадигматика // Лингвистический энциклопедический словарь. - М.: Советская энциклопедия, 1990. - С. 366 - 367.

7. Кумыкско-русский словарь: Более 30000 слов. Сост. Б.Г. Бамматов, Н.Э. Гаджиахмедов.- Махачкала: ИЯЛИ ДНЦ РАН, 2013. - 523 с.

8. Ожегов С.И. Словарь русского языка: 70000 слов. Под ред Н.Ю. Шведовой. 22-е изд., стер. - М.: Русский язык, 1990. - 921 с.

9. Русско-кумыкский словарь: Более 40000 слов. Под ред. Б.Г. Бамматова. - Махачкала: ДНЦ РАН, 1997. - 1754 с.

10. Филимоненко С.А. Парадигматические отношения звукоподражательных глаголов немецкого языка // Вестник СПбУ. Сер.9. Вып. 3. Ч. ІІ. - С. 221 - 225.

11. Хоменко 0.Е. Исследование синонимичных лексем с полем «страх» в толковых словарях // Мир на Северном Кавказе через языки, образование, культуру. Материалы IV Международного конгресса 21 - 24 сентября 2004 г. - Пятигорск, 2004. - С. 170 - 172.

12. Шляхова С.С. Дребезги языка: Словарь русских фоносемантических аномалий. - Пермь: Пермский государственный педагогический университет, 2004. $-226 c$. 